\title{
OcorRência de Espécies daninhas em Função de Sucessões de Cultivo $^{1}$
}

\author{
Occurrence of Weed Species under Crop Succession
}

\author{
CONCENÇO, G. ${ }^{2}$, CECCON, G. ${ }^{3}$, CORREIA, I.V.T. ${ }^{4}$, LEITE, L.F. ${ }^{4}$ e ALVES, V.B. ${ }^{4}$
}

\begin{abstract}
RESUMO - Objetivou-se neste trabalho avaliar a composição da comunidade infestante na cultura da soja, em função de sucessões de culturas por distintos períodos (uma ou três safras consecutivas). O ensaio foi instalado em campo na Embrapa Agropecuária Oeste, Dourados, MS. Foram avaliados cinco tratamentos de outono-inverno com histórico de uma ou três safras de implantação: milho solteiro - $90 \mathrm{~cm}$ entrelinhas; milho solteiro $-45 \mathrm{~cm}$ entrelinhas; consórcio milho + Brachiaria ruziziensis; Brachiaria ruziziensis solteira; e feijãocaupi. No final do mês de setembro de 2011, as áreas foram dessecadas com glyphosate para semeadura da soja; 30 dias após a dessecação, foram realizadas as avaliações. A caracterização fitossociológica das plantas daninhas estimou a abundância, a frequência, a dominância e o indice de valor de importância de cada espécie em cada área. As áreas foram ainda intraanalisadas quanto à diversidade de espécies, pelos indices de Simpson e Shannon-Weiner, e intercaracterizadas pela matriz de similaridade de Jaccard, pelo método UPGMA. O cultivo da soja deve ser seguido pela semeadura de espécie que proporcione elevada quantidade de palha residual na entressafra, com distribuição uniforme na superficie do solo. Essa palhada deve ser formada por resíduos de plantas com elevada relação C/N. Neste estudo, os sistemas de consórcio milho+braquiária, ou mesmo braquiária solteira, resultaram em menor nivel de infestação por plantas daninhas em áreas de sucessão à soja, ao longo do tempo de utilização.
\end{abstract}

Palavras-chave: safrinha, fitossociologia, diversidade, similaridade.

\begin{abstract}
This study aimed to evaluate the composition of weed communities in the soybean culture under cultivation of distinct commercial crops, grown for one or three subsequent years, without crop rotation. The experiment was installed under field conditions at Western Agriculture Embrapa, Dourados, Brazil. Five fall-wintertreatments, planted over one or three subsequent years, were evaluated: corn planted $90 \mathrm{~cm}$ between rows; corn planted $45 \mathrm{~cm}$ between rows, intercropped corn + Brachiaria ruziziensis, B. ruziziensis alone, and Cowpea. At the end of September 2011, all areas were desiccated with glyphosate, with evaluation being carried out 30 days after the first desiccation. The phyto-sociological characterization of the weed communities was based on abundance, frequency, dominance, and importance index of each species in the community. Areas were also intra-characterized by the diversity coefficients of Simpson and Shannon-Weiner and inter-characterized by the similarity matrix of Jaccard, through cluster analysis by the UPGMA method. Soybean sowing should be followed by sowing a species which allows accumulation of high amounts of residual dry mass on the soil surface, and this dry mass should present high $C / N$ ratio. At this study, the intercropped corn $+\boldsymbol{B}$. ruziziensis, or even $\boldsymbol{B}$. ruziziensis alone, planted following soybean, allowed lower infestation levels by weed species after three years of cultivation.
\end{abstract}

Keywords: second crop, phyto-sociology, diversity, similarity.

Recebido para publicação em 4.9.2012 e aprovado em 18.1.2013.

2 Engo-Agrōe, D.Sc. em Fitotecnia, Pesquisador da Embrapa Agropecuária Oeste, Dourados-MS, Área de Sistemas de Produção Sustentáveis - Manejo Integrado de Plantas Espontâneas, <germani@cpao.embrapa.br>; ${ }^{3}$ Engo-Agr ${ }^{\circ}$., D.Sc. em Agricultura, Pesquisador da Embrapa Agropecuária Oeste, Dourados-MS, Área de Sistemas de Produção Sustentáveis - Sistemas Integrados de Cultivo, <gessi@cpao.embrapa.br>; ${ }^{4}$ Estudantes de Agronomia, estagiários da Embrapa Agropecuária Oeste, Dourados-MS. 


\section{INTRODUÇÃO}

Estudos relacionados ao comportamento social de espécies vegetais infestantes são fundamentais para dar suporte a uma agricultura sustentável em solos tropicais, uma vez que a interferência dessas espécies pode causar significativas perdas de produtividade, especialmente em culturas com menor capacidade de competição por recursos com as espécies invasoras. Um dos mecanismos que asseguram a sobrevivência de uma determinada espécie em ambientes que constantemente sofrem distúrbios, sobretudo para espécies anuais, é o elevado número de sementes produzidas por plantas que escapam dos métodos de controle. Deuber (1992) cita várias espécies com alta produção de sementes, como Amaranthus spp. - 120.000 sementes por planta, Galinsoga parviflora-30.000 sementes por planta e Portulaca oleracea- 53.000 sementes por planta. Em ambientes adversos e que sofrem constantes distúrbios, estas espécies normalmente tendem a aumentar sua frequência de ocorrência, cobrindo a maior parte da área e causando problemas às culturas comerciais (Norsworthy et al., 2001).

Em clima tropical seco e em ambiente de clima temperado, as culturas são instaladas na estação de cultivo mais adequada e as áreas, normalmente, permanecem sem cultivo econômico pelo resto do ano (Alvarenga et al., 2001). Vários estudos indicam que, caso essas áreas sejam mantidas sem cobertura vegetal no período em que não há cultivos comerciais, a infestação por plantas daninhas tende a ser mais severa na estação de cultivo subsequente, devido ao espaço disponível para seu estabelecimento e maior acesso das plântulas à luz (Silva et al., 2007). Nesse contexto, essas espécies daninhas podem produzir mais sementes, as quais, ao serem adicionadas ao banco de sementes do solo, representarão a infestação futura.

Por outro lado, mesmo com alterações no número de indivíduos e na composição das espécies infestantes, proporcionadas pelo uso de coberturas no inverno e/ou entressafra, algumas espécies em particular podem apresentar variabilidade na resposta a práticas de controle (Voll et al., 2005). Compreender não somente o nivel de ocorrência, mas também a composição da comunidade infestante dentro de cada sistema de rotação de culturas, é importante para subsidiar o delineamento de um conjunto de práticas de manejo que resultará em controle eficiente das espécies problemáticas. Lançando mão da capacidade inata das plantas de culturas de suprimir o crescimento de outras espécies, é possivel maximizar a produtividade da cultura significativamente e reduzir tanto as despesas com o controle de plantas daninhas, como os riscos negativos ao meio ambiente (Velykis \& Satkus, 2006).

Existem dois mecanismos principais que podem ser relacionados à menor infestação e emergência defasada de plântulas em áreas onde plantas de cobertura são utilizadas na entressafra, sendo o primeiro atribuído à capacidade de produção de substâncias alelopáticas, que podem tanto causar inibição direta do crescimento vegetal (Putnam \& DeFrank, 1983; Friebe et al., 1995, Tesio et al., 2010), como estimular fungos endofiticos capazes de atacar sementes no banco do solo (Voll et al., 2004). O segundo mecanismo está relacionado ao efeito de cobertura, sombreando plântulas das espécies daninhas. O último mecanismo é geralmente mais eficiente em suprimir o crescimento (porém não a germinação) de plântulas com metabolismo do carbono pelo ciclo $\mathrm{C}_{4}$ (Silva et al., 2007). Cita-se ainda que, em solos com a presença de cobertura vegetal, é comum o desenvolvimento de insetos predadores de sementes de plantas daninhas, que contribuem para minimizar a presença de determinadas espécies daninhas (Gallandt et al., 2005).

Estudos fitossociológicos permitem avaliar a composição de espécies de um dado dossel vegetal e estimar a abundância (ou densidade), frequência e dominância (ou cobertura) de determinada comunidade vegetal. Com esses parâmetros sinecológicos também é possivel estimar a importância relativa de cada espécie na área e, assim, prever danos às culturas que serão semeadas, provocados por cada fração da infestação (Gomes et al., 2010). Além disso, é possível estudar cada área ou tratamento em função da variedade de espécies presentes ao utilizar indices de diversidade, bem como comparar tratamentos ou áreas entre si, pelo uso de índices sinecológicos de 
similaridade. Essa riqueza de informações acerca da comunidade vegetal em determinada área subsidia o cientista a compreender que tipos de interação estão ocorrendo e quais espécies estão sendo selecionadas pelo sistema de manejo e práticas adotados na área.

Objetivou-se com este estudo avaliar a composição da comunidade infestante sob cultivo de diferentes culturas comerciais na ausência de rotação de culturas, manejadas por distintos períodos de implantação (um e três anos).

\section{MATERIAL E MÉTODOS}

O ensaio foi instalado em condições de campo, na área experimental da Embrapa Agropecuária Oeste, Dourados, Mato Grosso do Sul, localizada nas coordenadas de $22^{\circ} 16^{\prime} \mathrm{S}$, $54^{\circ} 49^{\prime} \mathrm{W}$ e $408 \mathrm{~m}$ acima do nível do mar. O experimento foi montado em delineamento experimental completamente casualizado em parcelas subdivididas, com quatro repetições. $\mathrm{Na}$ parcela principal foram alocadas as datas de implantação e, na subparcela, os tratamentos de outono-inverno, em unidades experimentais medindo $10 \times 25 \mathrm{~m}$.

Foram avaliados cinco tratamentos de outono-inverno, implantados em 2010/11 (primeiro ano, tratamentos que terminam em “1") ou em 2008/09, 2009/10 e 2010/11 (três anos, tratamentos que terminam em “ 3 "): (T1-1 e T1-3) milho solteiro semeado a $90 \mathrm{~cm}$ entrelinhas; (T2-1 e T2-3) milho solteiro semeado a $45 \mathrm{~cm}$ entrelinhas; (T3-1 e T3-3) consórcio milho + Brachiaria ruziziensis; (T4-1 e T4-3) Brachiaria ruziziensis solteira; e (T5-1 e T5-3) feijão-caupi.

Todos os tratamentos foram anualmente semeados durante o primeiro decêndio de março, sendo sempre precedidos do cultivo de soja Roundup Ready ${ }^{\circledR}$ entre outubro e fevereiro, semeada sobre resteva do ano anterior. Durante o cultivo de soja nenhum herbicida com efeito residual foi utilizado.

O milho híbrido BRS-1010 foi semeado em linhas espaçadas de $90 \mathrm{~cm}$ ou $45 \mathrm{~cm}$, dependendo do tratamento, de forma a se obter população de 45.000 plantas por hectare em ambos os espaçamentos entrelinhas. A mesma densidade de milho foi estabelecida nos consórcios milho + Brachiaria ruziziensis. Para braquiária foi utilizada uma densidade de 200.000 plantas por hectare quando em consórcio, semeada em linhas intercaladas às do milho, e o dobro de sementes quando em plantio solteiro. No consórcio, tanto as linhas do milho como as da braquiária foram espaçadas em $90 \mathrm{~cm}$; dessa forma, o espaçamento entre a linha de milho e a de braquiária adjacente foi de $45 \mathrm{~cm}$. Os tratamentos com feijão-caupi foram plantados com a variedade BRS Guariba em linhas espaçadas de $45 \mathrm{~cm}$, com densidade de 200.000 plantas ha ${ }^{-1}$.

No final do mês de setembro de 2011, após três anos de cultivo, as áreas foram dessecadas com $1.440 \mathrm{~g} \mathrm{ha}^{-1}$ de equivalente ácido de glyphosate para a semeadura da soja a ser realizada no início da segunda quinzena de outubro; trinta dias após a dessecação, foram conduzidas as avaliações em todas as parcelas. Em cada parcela foram obtidas quatro subamostras, pelo método de amostragem dos Quadrados Aleatórios, proposto por Barbour et al. (1998).

A caracterização fitossociológica das plantas daninhas emergidas do banco de sementes (rebrotes de plantas não completamente controladas pelo glyphosate foram desconsiderados) foi feita nos pontos amostrados, conforme previamente descritos, em área de $1 \mathrm{~m}^{2} \mathrm{em}$ cada ponto. Em cada área, todas as plântulas e plantas emergidas foram identificadas, coletadas e armazenadas por espécie, sendo secas em estufa com circulação forçada de ar a $60{ }^{\circ} \mathrm{C}$, para posterior determinação da massa seca. Foram apresentados em histogramas o número de plantas e a massa seca total $\left(\mathrm{g} \mathrm{m}^{-2}\right)$ da comunidade infestante nos diferentes tratamentos, com os respectivos erros-padrão amostrais.

Para cada espécie, foram estimadas a abundância (número de indivíduos), a frequência (distribuição espacial da espécie) e a dominância (capacidade de acumular massa), apresentadas neste estudo somente em termos relativos. Com base nesses três parâmetros, o índice de valor de importância de cada espécie, em cada área, foi obtido segundo Pandeya et al. (1968) e Barbour et al. (1998). $\mathrm{O}$ indice de valor de importância (IVI) situa cada espécie daninha dentro da comunidade, em função da sua capacidade de causar danos 
(severidade de ocorrência), com base nos três parâmetros previamente citados. Devido ao número de tratamentos, para cada área do presente estudo, somente as quatro principais espécies daninhas (com base no valor de importância) foram apresentadas, sendo as demais agrupadas como "outras espécies". As áreas foram ainda intra-analisadas quanto à diversidade de espécies pelos índices de Simpson (D) e Shannon-Weiner (H') (Barbour et al., 1998).

Posteriormente, as áreas foram comparadas entre si pelo coeficiente binário assimétrico de similaridade de Jaccard. Com base nos coeficientes de Jaccard, foi elaborada a matriz de similaridade, e a partir desta foi obtida a matriz de dissimilaridade (1-similaridade). A análise multivariada de agrupamento hierárquico foi efetuada a partir da matriz de dissimilaridade, pelo método UPGMA (Unweighted Pair Group Method with Arithmethic Mean) (Sneath $\&$ Sokal, 1973). O nivel crítico para separação dos grupos na análise de agrupamento foi baseado na média aritmética das similaridades na matriz original de Jaccard (Barbour et al., 1998), desconsiderando os pontos de cruzamento entre as mesmas áreas na matriz. A validação dos grupos foi feita pelo coeficiente de correlação cofenética (Sokal \& Rohlf, 1962), obtido por correlação linear de Pearson entre a matriz original de dissimilaridade e a matriz cofenética. Os coeficientes de diversidade e similaridade, bem como a análise de agrupamento (Cluster), foram obtidos no ambiente estatístico R (R-development, 2011).

Todas as fórmulas e procedimentos, tanto de amostragem das áreas como de descrição das comunidades e agrupamento das espécies, seguiram o preconizado por Barbour et al. (1998) para análises sinecológicas.

\section{RESULTADOS E DISCUSSÃO}

Constataram-se diferenças na presença de espécies infestantes após um ano de manejo diferenciado na entressafra, quanto ao nível de infestação destas na safra de soja subsequente (Figura 1A, B). De maneira geral, culturas tradicionalmente com cobertura vegetal do solo deficiente, como milho e feijãocaupi, resultaram em maior presença dessas espécies daninhas. Embora o milho seja capaz de produzir quantidades significativas de massa seca, a cobertura do solo proporcionada por essa cultura, em crescimento, pode ser deficiente, porque a massa seca é significativamente concentrada nos colmos, com poucas folhas cobrindo o solo (Andrade, 1995). Atualmente, recomenda-se a utilização do consórcio milho-braquiária, de forma a maximizar a
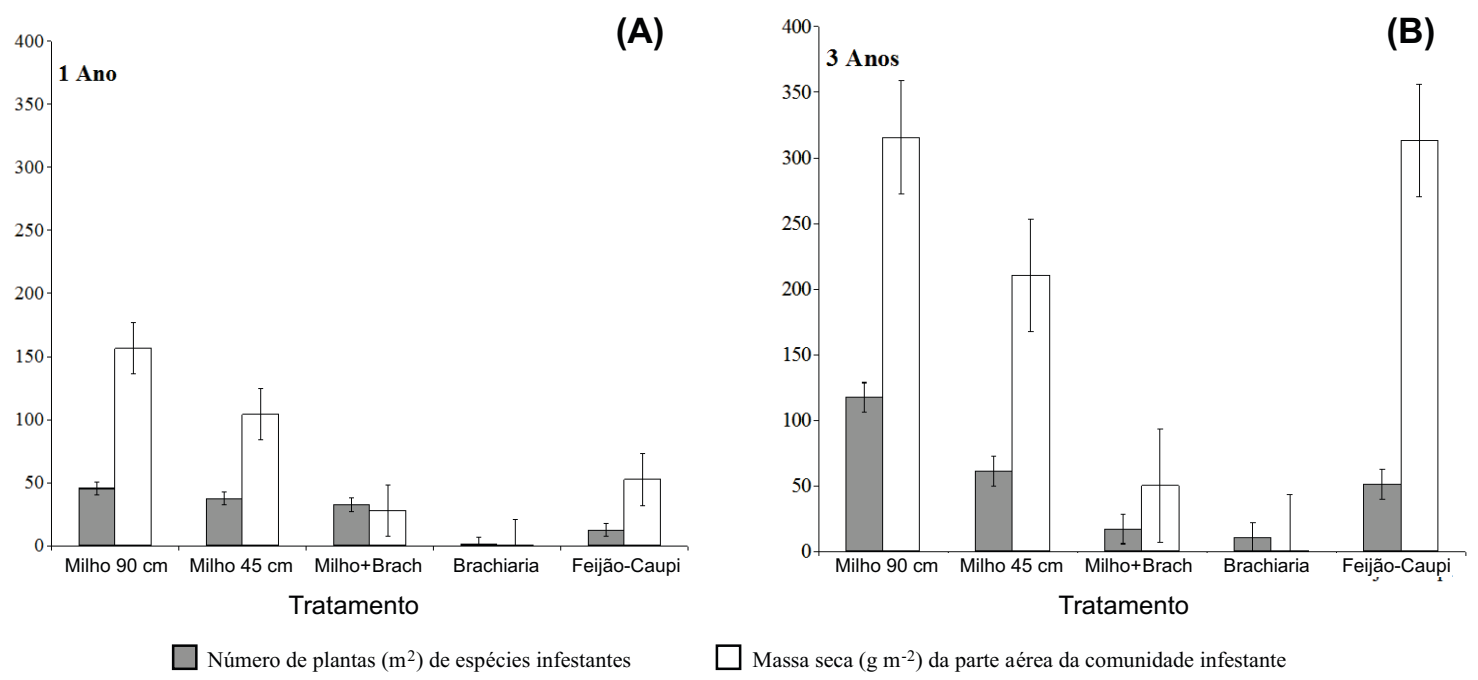

Tratamentos foram implantados anualmente na segunda safra, sendo sempre precedidos pelo cultivo da soja. Embrapa Agropecuária Oeste, Dourados-MS, 2012.

Figura 1 - Número de plantas $\left(\mathrm{m}^{2}\right)$ de espécies infestantes e massa seca $\left(\mathrm{g} \mathrm{m}^{-2}\right)$ da parte aérea da comunidade infestante, na présemeadura da cultura da soja em rotação com diferentes cultivos de outono-inverno ( $\mathrm{A}=1$ ano; $\mathrm{B}=3$ anos). 
formação e a distribuição dos resíduos vegetais na área após o cultivo do milho (Ceccon, 2011). O feijão-caupi, por outro lado, embora produza quantidades significativas de massa seca, é rapidamente decomposto no solo devido à baixa relação $\mathrm{C} / \mathrm{N}$ de sua massa seca (Azevedo \& Spehar, 2002).

Observou-se, após um ano de manejo, que o milho solteiro cultivado a $90 \mathrm{~cm}$ entrelinhas resultou em número de plantas similar ao observado após cultivo de milho+braquiária, porém a severidade de infestação (massa seca acumulada pelas infestantes) foi cerca de três vezes superior no tratamento com milho solteiro. Com cultivo de milho a $45 \mathrm{~cm}$ entrelinhas, a severidade da infestação foi aproximadamente $30 \%$ menor em comparação ao milho solteiro a $90 \mathrm{~cm}$, embora o número de plantas daninhas tenha sido ainda similar (Figura 1A). A introdução do feijão-caupi mostrou-se mais efetiva que os cultivos de milho na redução da ocorrência de plantas daninhas, tanto em número de plantas quanto em produção de matéria seca.

Ao atingir três anos de sucessão soja-cultivos (Figura 1B), observou-se que as áreas com presença de braquiária, solteira ou consorciada com milho, mantiveram niveis de infestação equivalentes aos observados no primeiro ano de avaliação, enquanto a opção pelo uso de milho solteiro, em ambos os espaçamentos entre linhas, e feijão-caupi resultou em niveis de infestação superiores aos inicialmente presentes na área. A escolha pelo consórcio milho-braquiária pós-soja, por três anos, resultou em 22 plantas e $50 \mathrm{~g} \mathrm{~m}^{-2}$ de massa seca da comunidade infestante; o milho solteiro a $90 \mathrm{~cm}$ entrelinhas resultou em 110 plantas e $322 \mathrm{~g} \mathrm{~m}^{-2}$ de massa seca das infestantes (diferenças significativas de acordo com os erros-padrão amostrais). A cultura do milho implantado a $45 \mathrm{~cm}$ entrelinhas resultou em menor nivel de infestação que o milho a $90 \mathrm{~cm}$, porém com alta infestação quando comparado às áreas com presença de braquiária, solteira ou no consórcio (Figura 1).

Pode-se observar que, para todos os sistemas de cultivo que não envolvem braquiária, a infestação de plantas daninhas - tanto em termos de número de indivíduos quanto de cobertura da área - se agravou após três anos de manejo (Figura 2). Outro ponto a ser observado é a inibição causada pelo feijão-caupi sobre o número de plantas daninhas estabelecido na área, que não se refletiu em menor acúmulo de massa seca. Isso pode indicar algum potencial alelopático dessa cultura sobre a flora infestante. É conhecida a produção de um potente inibidor de tripsina,
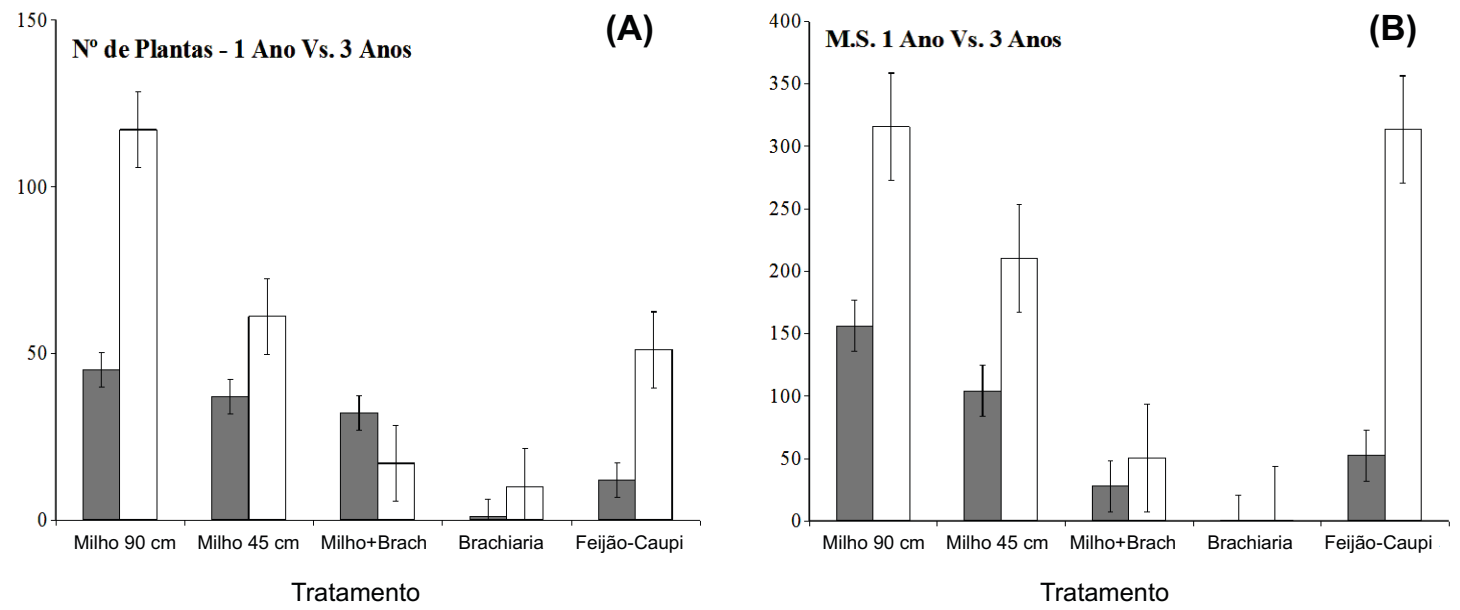

Primeiro cultivo

Cultivo por três safras.

Tratamentos foram implantados anualmente na segunda safra, sendo sempre precedidos pelo cultivo da soja. Embrapa Agropecuária Oeste, Dourados-MS, 2012.

Figura 2 - Número de plantas (A) e massa seca $\left(\mathrm{g} \mathrm{m}^{-2}\right)$ da parte aérea da comunidade infestante (B) na pré-semeadura da cultura da soja em rotação com diferentes cultivos de outono-inverno. 
eficiente inseticida, pelo feijão-caupi (Mairesse, 2005), bem como o efeito alelopático do extrato alcoólico dessa espécie sobre a germinação e o crescimento de determinadas espécies daninhas (Hill et al., 2007).

Nas análises fitossociológicas são apresentadas somente as quatro principais espécies infestantes em cada área, sendo as demais agrupadas como "Outras espécies". Como regra geral, observa-se que a maior parte das espécies infestantes identificadas, entre as quatro mais importantes no primeiro ano, normalmente não voltaram a se repetir como as mais importantes no mesmo tratamento após três anos de cultivo da mesma espécie (Tabela 1). Somente na cultura do milho implantado a $45 \mathrm{~cm}$ entrelinhas a espécie Leonotis nepetifolia foi presente após três anos, ao passo que a espécie Amaranthus hybridus se repetiu nas áreas com presença de braquiária solteira e de feijão-caupi após o mesmo período.

$\mathrm{Na}$ área de cultivo de milho solteiro a $90 \mathrm{~cm}$ entrelinhas (Tabela 1), as espécies picão-preto (B. pilosa), caruru (A. viridis), ervade-botão (Eclipta alba) e leiteiro (Euphorbia heterophylla) foram as mais importantes no primeiro ano de cultivo; após três anos de manejo, houve diferenças na dominância das espécies infestantes, sendo o cordão-de-frade (L. nepetifolia), a maria-pretinha (Solanum americanum), a trapoeraba (Commelina benghalensis) e a poaia-branca (Richardia brasiliensis) as de maior importância. Salienta-se ainda que, após três anos de manejo, as quatro principais espécies daninhas identificadas foram mais importantes $(71,1 \%$ de importância da infestação total) que as quatro espécies mais importantes no primeiro ano do estudo $(60,9 \%$ de importância da infestação total). As diferenças nos IVIs também se refletiram na diversidade de espécies nessas áreas (Tabela 2). Após um ano, na área cultivada com milho solteiro a $90 \mathrm{~cm}$, observaramse indices de diversidade de 0,83 e 3,11, respectivamente para Simpson e ShannonWeiner; a área com três anos de cultivo apresentou valores de 0,71 e 2,42 para os mesmos índices. O número de espécies encontrado em cada área - 12 após um ano e 13 após três anos de cultivo de milho solteiro a $90 \mathrm{~cm}$ entrelinhas - não reflete diretamente a diversidade na área, ficando este trabalho a cargo dos indices de diversidade (Barbour et al., 1998), que também consideram o balanço de ocorrência entre as espécies.

Souza (2004) afirma que modelos agrícolas com base em utilização de agroquímicos tendem a diminuir a diversidade de espécies dentro do sistema agrícola, reduzindo sua sustentabilidade a longo prazo. Consistente com a teoria da sucessão ecológica, Murphy et al. (2006), estudando o banco de sementes e a infestação de superficie de diversos sistemas de cultivo em várias fazendas, concluíram que áreas em pousio resultaram no maior indice de diversidade de espécies após seis anos de manejo, enquanto sistemas conservacionistas, como plantio direto, foram eficientes em reduzir o número de propágulos de espécies daninhas no banco do solo.

$\mathrm{Na}$ área com o cultivo de milho solteiro a $45 \mathrm{~cm}$ entrelinhas, apenas a espécie cordãode-frade permaneceu entre as quatro espécies infestantes mais importantes, tanto após um como após três anos de manejo (Tabela 1). Caruru, corda-de-viola (Ipomoea grandifolia) e mentruz (Lepidium virginicum), entre as mais importantes no primeiro ano, foram substituídas por trapoeraba, mastruço (Apium leptophyllum) e poaia-branca após três anos de manejo. O cultivo de milho adensado, ao contrário do observado para o espaçamento de $90 \mathrm{~cm}$, resultou em maiores índices de diversidade de espécies após três anos de cultivo, em comparação à área com apenas um ano de manejo (Tabela 2). O número de espécies também diferiu (seis após um ano e dez após três anos de manejo diferenciado). Isso mostra que, no primeiro ano de introdução de uma cultura e de suas práticas de manejo associadas, pode ocorrer redução "momentânea" na diversidade (ou até na quantidade) em resposta a uma ação específica (redução de espaçamento), mas que, com a continuidade do monocultivo após três anos, as espécies se adaptam a esse novo sistema cultural e ambiente.

A área implantada com o consórcio da cultura do milho a $90 \mathrm{~cm}$ entrelinhas intercalado com linhas de braquiária também resultou em mudanças nas quatro espécies daninhas mais importantes na área (Tabela 1). 
Tabela 1 - Abundância, frequência, dominância e índice de valor de importância de espécies daninhas na cultura da soja em rotação com diferentes cultivos de outono-inverno, pelo período de um e três anos após implantação. Embrapa Agropecuária Oeste, Dourados-MS, 2012

\begin{tabular}{|c|c|c|c|c|c|c|c|c|c|}
\hline Espécie & $\mathrm{AB}(\%)$ & $\mathrm{FR}(\%)$ & $\mathrm{DO}(\%)$ & $\operatorname{IVI}(\%)$ & Espécie & $\mathrm{AB}(\%)$ & $\mathrm{FR}(\%)$ & $\mathrm{DO}(\%)$ & $\operatorname{IVI}(\%)$ \\
\hline \multicolumn{5}{|c|}{ Milho $90 \mathrm{~cm} 1$ ano de cultivo } & \multicolumn{5}{|c|}{ Milho $90 \mathrm{~cm} 3$ anos de cultivo } \\
\hline B. pilosa & 35,56 & 17,39 & 30,30 & 27,75 & L. nepetifolia & 48,72 & 13,04 & 9,34 & 23,70 \\
\hline A. viridis & 8,89 & 8,70 & 16,47 & 11,35 & S. americanum & 7,69 & 13,04 & 43,77 & 21,50 \\
\hline E.alba & 6,67 & 4,35 & 22,31 & 11,11 & C. benghalensis & 18,80 & 4,35 & 18,22 & 13,79 \\
\hline E. heterophylla & 6,67 & 8,70 & 16,80 & 10,72 & R. brasiliensis & 10,26 & 17,39 & 8,57 & 12,07 \\
\hline Outras espécies & 42,21 & 60,86 & 14,12 & 39,07 & Outras espécies & 14,53 & 52,18 & 20,10 & 28,93 \\
\hline \multicolumn{5}{|c|}{ Milho $45 \mathrm{~cm} 1$ ano de cultivo } & \multicolumn{5}{|c|}{ Milho $45 \mathrm{~cm} 3$ anos de cultivo } \\
\hline A. hybridus & 13,51 & 28,57 & 93,26 & 45,12 & C. benghalensis & 21,31 & 16,67 & 49,55 & 29,18 \\
\hline L. nepetifolia & 54,05 & 14,29 & 1,36 & 23,23 & A. leptophyllum & 32,79 & 16,67 & 16,19 & 21,88 \\
\hline I. grandifolia & 21,62 & 14,29 & 1,11 & 12,34 & R. brasiliensis & 13,11 & 11,11 & 8,28 & 10,83 \\
\hline L. virginicum & 5,41 & 14,29 & 0,84 & 6,84 & L.nepetifolia & 13,11 & 11,11 & 7,46 & 10,56 \\
\hline Outras espécies & 5,41 & 28,56 & 3,43 & 12,47 & Outras espécies & 19,68 & 44,44 & 18,52 & 27,55 \\
\hline \multicolumn{5}{|c|}{ Milho + braquiária 1 ano de cultivo } & \multicolumn{5}{|c|}{ Milho + braquiária 3 anos de cultivo } \\
\hline R.brasiliensis & 59,38 & 18,18 & 34,70 & 37,42 & A. hybridus & 23,53 & 20 & 70,99 & 38,17 \\
\hline B. pilosa & 9,38 & 18,18 & 18,20 & 15,25 & E. heterophylla & 23,53 & 20 & 15,60 & 19,71 \\
\hline C. echinatus & 6,25 & 9,09 & 25,84 & 13,73 & L. nepetifolia & 29,41 & 20 & 8,38 & 19,26 \\
\hline C. benghalensis & 6,25 & 18,18 & 4,40 & 9,61 & S. oleraceus & 5,88 & 10 & 3,98 & 6,62 \\
\hline Outras espécies & 18,74 & 36,37 & 16,86 & 23,99 & Outras espécies & 17,65 & 30,00 & 1,05 & 16,23 \\
\hline \multicolumn{5}{|c|}{ Braquiária 1 ano de cultivo } & \multicolumn{5}{|c|}{ Braquiária 3 anos de cultivo } \\
\hline \multirow{2}{*}{ A. hybridus } & \multirow{2}{*}{100,00} & \multirow{2}{*}{100,00} & \multirow{2}{*}{100,00} & \multirow{2}{*}{100,00} & A. hybridus & 80,00 & 50,00 & 87,10 & 72,37 \\
\hline & & & & & I. Purpurea & 20,00 & 50,00 & 12,90 & 27,63 \\
\hline \multicolumn{5}{|c|}{ Feijão-caupi 1 ano de cultivo } & \multicolumn{5}{|c|}{ Feijão-caupi 3 anos de cultivo } \\
\hline A. viridis & 8,33 & 8,33 & 48,21 & 21,63 & R. brasiliensis & 19,61 & 23,08 & 63,43 & 35,37 \\
\hline A. sativa & 25,00 & 25,00 & 10,06 & 20,02 & A. hybridus & 11,76 & 15,38 & 24,02 & 17,06 \\
\hline D. horizontalis & 8,33 & 8,33 & 24,84 & 13,83 & C. benghalensis & 19,61 & 23,08 & 1,42 & 14,70 \\
\hline A. hybridus & 16,67 & 16,67 & 2,32 & 11,89 & L. nepetifolia & 19,61 & 15,38 & 1,50 & 12,17 \\
\hline Outras espécies & 41,67 & 41,67 & 14,57 & 32,63 & Outras espécies & 29,41 & 23,08 & 9,63 & 20,70 \\
\hline
\end{tabular}

NOTA: Todos os valores da tabela estão em porcentagem, para facilitar a compreensão e direta interpretação dos dados. $\mathrm{AB}=$ abundância; $\mathrm{FR}=$ frequência; DO = dominância; IVI = índice de valor de importância. Para obter os valores de IVI tradicionalmente utilizados $(\mathrm{IVI}=\mathrm{AB}+\mathrm{FR}+\mathrm{DO})$, basta multiplicar o valor de $\mathrm{IVI}(\%)$ por três.

Destaca-se a presença de poaia, picão-preto, capim-carrapicho (Cenchrus echinatus) e trapoeraba após um ano de cultivo, que foram substituídos por caruru, leiteiro, cordão-defrade e serralha (Sonchus oleraceus). A diversidade de espécies nas áreas de consórcio (Tabela 2) foi maior após três anos de manejo (de 0,62/2,08 para 0,79/2,46, respectivamente para Simpson e Shannon-Weiner), embora os IVIs indiquem que as quatro principais espécies infestantes identificadas foram mais presentes nas áreas de consórcio após três anos de manejo que em área com apenas um ano (Tabela 1). 
Tabela 2 - Coeficientes de diversidade de Simpson e Shannon-Weiner na cultura da soja em rotação com diferentes cultivos de outonoinverno, pelo período de um e três anos após implantação. Embrapa Agropecuária Oeste, Dourados-MS, 2012

\begin{tabular}{|l|c|c|c|c|c|c|}
\hline \multirow{2}{*}{ Tratamento } & \multicolumn{3}{|c|}{1 Ano } & \multicolumn{3}{c|}{3 Anos } \\
\cline { 2 - 8 } & $\begin{array}{c}\text { Número de } \\
\text { espécies }\end{array}$ & Simpson & Shannon-Weiner & $\begin{array}{c}\text { Número de } \\
\text { espécies }\end{array}$ & Simpson & Shannon-Weiner \\
\hline Milho 90 cm & 12 & 0,83 & 3,11 & 13 & 0,71 & 2,42 \\
\hline Milho 45 cm & 6 & 0,64 & 1,86 & 10 & 0,80 & 2,65 \\
\hline Milho+braquiária & 8 & 0,62 & 2,08 & 7 & 0,79 & 2,46 \\
\hline Braquiária & 1 & 0,00 & 0,00 & 2 & 0,32 & 0,72 \\
\hline Feijão-caupi & 8 & 0,85 & 2,86 & 7 & 0,81 & 2,53 \\
\hline
\end{tabular}

NOTA: Os coeficientes de diversidade consideram também a grandeza das diferenças entre os níveis de ocorrência de cada espécie na área; portanto, esses índices não são diretamente proporcionais ao número de espécies identificado naquela área.

$\mathrm{Na}$ presença de braquiária solteira, os levantamentos mostraram menor índice absoluto de infestação, seguido pelo consórcio milho-braquiária (Figura 1). Na área de braquiária solteira (Tabela 1), ocorreu somente caruru após o primeiro ano de cultivo, e essa espécie representou $72,4 \%$ da infestação após três anos de manejo. A espécie Ipomoea purpurea (corda-de-viola) também ocorreu após três anos. Salienta-se, no entanto, que esses dados devem ser interpretados em conjunto com o baixo nível de infestação na área de braquiária solteira (Figuras 1 e 2). Em relação à diversidade (Tabela 2), ela foi nula após um ano de braquiária (somente uma espécie infestante) e muito baixa após três anos de manejo, com somente duas espécies daninhas presentes. Esses dados refletem a possivel alta capacidade de produção de massa seca e cobertura do solo obtida com o uso de braquiária.

A área com cultivo de feijão-caupi também apresentou somente uma espécie daninha em comum (caruru) entre as áreas com um e três anos de manejo, destacando-se ao final desse período o aumento da importância de poaiabranca (35\% da infestação) como causadora de interferência (Tabela 1). A trapoeraba, outra espécie daninha com tolerância ao glyphosate, também foi privilegiada com o cultivo sucessivo do feijão-caupi. Enquanto após um ano de cultivo $67,4 \%$ da infestação foi atribuída às quatro principais espécies daninhas, após três anos de manejo, 79,3\% da infestação foi ocasionada pelas quatro principais infestantes encontradas no experimento (Tabela 1). A diversidade na área foi equiparável aos índices observados para o tratamento de milho solteiro a $90 \mathrm{~cm}$ entrelinhas (Tabela 2), embora com menor número de espécies ocorrentes. Isso significa que, no tratamento com milho solteiro a $90 \mathrm{~cm}$, muitas das espécies ocorrentes apresentaram número baixo de exemplares, ao passo que no tratamento de feijão-caupi a ocorrência mais balanceada do número de indivíduos de cada espécie resultou em maior indice de diversidade (Tabela 2). Isso evidencia que o uso do monocultivo do milho pode selecionar poucas espécies daninhas na área, porém estas serão de maior impacto por estarem altamente adaptadas ao sistema de cultivo (Silva et al., 2007).

A análise de agrupamento por similaridade (Figura 3) com base no coeficiente de Jaccard indicou a existência de cinco grupos de áreas, com características homogêneas dentro de cada grupo (Figura 3). Pelo critério da média aritmética da matriz original de similaridades, a área com um ano de braquiária solteira (B-1) é o único componente do primeiro grupo; devido ao baixo número de espécies daninhas encontrado nesta área, ela foi agrupada separadamente das demais em qualquer nível de similaridade. O segundo grupo foi formado pelas áreas com três anos de braquiária, tanto solteira (B-3) como em consórcio com milho (MB-3); o terceiro e o quarto grupo também contaram com apenas um representante: milho solteiro a $45 \mathrm{~cm}$ no primeiro ano (M45-1) e caupi por um ano de cultivo $(\mathrm{C}-1)$, respectivamente; e o quinto grupo foi aquele com maior número de componentes, reunindo as 
demais áreas que não apresentaram características distintas o suficiente para formarem grupos separados. Neste grupo foram incluídas as áreas de milho solteiro a $45 \mathrm{~cm}$ por três anos (M45-3), milho solteiro a $90 \mathrm{~cm}$ entrelinhas por um (M90-1) e por três (M90-3) anos de cultivo, feijão-caupi por três anos e milho + braquiária no primeiro ano (MB-1) (Figura 3).

Como a análise de agrupamento (Figura 3) baseia-se no nivel de semelhança de ocorrência de espécies, ele não está diretamente relacionado aos níveis de infestação apresentados na Figura 1. No entanto, é possivel observar certa relação entre os coeficientes de diversidade intra-áreas (Tabela 2), bem como a similaridade entre áreas (Figura 3). Em termos gerais, áreas com menor diversidade foram separadas daquelas com diversidades equivalentes. Embora não diretamente proporcionais, ambos os coeficientes baseiamse na mesma origem - composição das espécies infestantes.

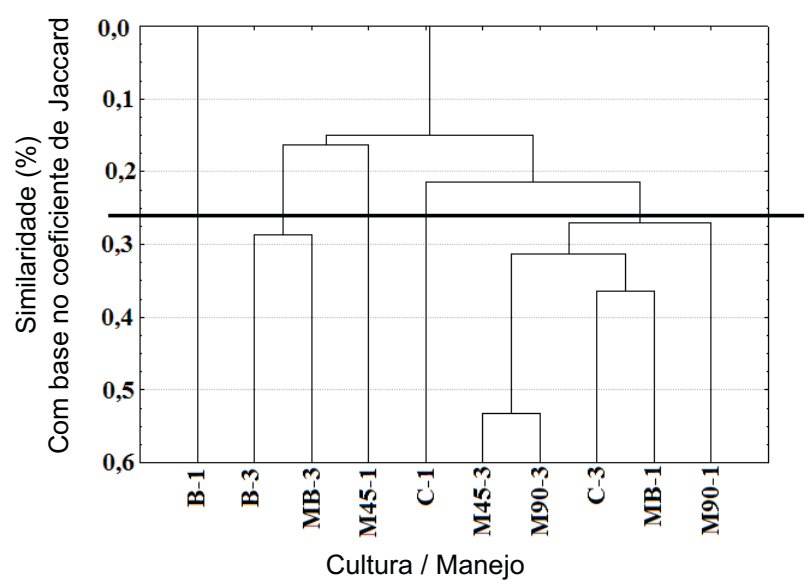

M90 $=$ milho solteiro a $90 \mathrm{~cm}$ entrelinhas; M45 $=$ milho solteiro a $45 \mathrm{~cm}$ entrelinhas; $\mathrm{MB}=$ consórcio milho-braquiária em linhas intercaladas, espaçadas em $45 \mathrm{~cm} ; \mathrm{B}=$ braquiária solteira; $\mathrm{C}=$ feijão-caupi. Números ao final identificam tempo de cultivo, sendo $1=$ primeiro ano de cultivo, e $3=$ terceiro ano de cultivo

Figura 3 - Análise multivariada de agrupamento (cluster analysis) para as dez áreas submetidas a distintos cultivos sem rotação de culturas. O ponto de corte para formação dos grupos foi obtido pelo método da média aritmética da matriz de similaridade de Jaccard, desconsiderando cruzamentos entre as mesmas áreas. O agrupamento foi estabelecido com base no método UPGMA. Embrapa Agropecuária Oeste, Dourados-MS, 2012
Com base nas informações apresentadas, é possivel ressaltar que o nível de infestação em sistemas de monocultivo aumenta ao longo dos anos e que a semeadura de braquiária após a soja, tanto solteira como em consórcio com milho, é capaz de manter o nível de infestação próximo ao observado no início do monocultivo de soja, ou da sucessão contínua soja-milho+braquiária. Em sistemas com menor ocupação do solo pós-soja, como milho $90 \mathrm{~cm}$ solteiro e feijão-caupi, a diversidade de espécies daninhas na área é diminuída, aumentando por consequência a importância das espécies mais adaptadas ao sistema de cultivo; sistemas de cultivo com menor tempo de implantação e/ou que proporcionem menor cobertura do solo durante o inverno tendem a ser similares quanto à composição da infestação por espécies daninhas.

Em suma, o cultivo da soja deve ser seguido pela semeadura de espécie que proporcione elevada quantidade de palha residual na entressafra, com distribuição uniforme na superficie do solo, e essa palhada na superfície do solo deve ser formada por resíduos de plantas com elevada relação C/N. Neste estudo, os sistemas de consórcio milho+braquiária, ou mesmo braquiária solteira, resultaram em menor nível de infestação por plantas daninhas em áreas de sucessão à soja, ao longo do tempo de utilização.

\section{LITERATURA CITADA}

ALVARENGA, R. C. et. al. Plantas de cobertura de solo para sistema plantio direto. Inf. Agropec., v. 22, n. 1, p. 25-36, 2001.

ANDRADE, F. H. Analysis of growth and yield of maize, sunflower and soybean grown at Balcarce, Argentina. Field Crops Res., v. 41, n. 1, p. 1-12, 1995

AZEVEDO, D. M. P.; SPEHAR, C. R. Decomposição da palhada de culturas para plantio no período de safrinha em solos de tabuleiros costeiros. Teresina: Embrapa Meio Norte, 2002. (Embrapa Meio Norte. Comunicado Técnico, 147)

BARBOUR, M. G. et al. Terrestrial plant ecology. Menlo Park: Benjamin/Cummings, 1998. 688 p.

CECCON, G. Dicas para implantação do consórcio milhobraquiária. R. Plantio Direto, v. 124, n. 1, p. 20-21, 2011.

Planta Daninha, Viçosa-MG, v. 31, n. 2, p. 359-368, 2013 
DEUBER, R. Ciência das plantas daninhas: fundamentos. Jaboticabal: FUNEP, 1992. v. 1. 431 p.

FRIEBE, A. et. al. Phytotoxins from shoot extracts and root exudates of Agropyron repens seedlings. Phytochemistry, v. 38, n. 5 , p. $1157-1159,1995$.

GALLANDT, E. R. et al. Effect of cover-cropping systems on invertebrate seed predation. Weed Sci., v. 53, n. 1, p. $69-76,2005$

GOMES, G. L. G. C. et al. Cadastramento fitossociológico de plantas daninhas na bananicultura. Planta Daninha, v. 28 n. 1, p. $61-68,2010$

HILL, E. C.; NGOUAJIO, M.; NAIR, M. G. Allelopathic potential of hairy vetch (Vicia villosa) and cowpea (Vigna unguiculata) acetate extracts on weeds and vegetables. Weed Technol., v. 21, n. 2, p. 437-444, 2007

MAIRESSE, L. A. S. Avaliação da bioatividade de extratos de espécies vegetais, enquanto excipientes de aleloquímicos. 2005. 340 f. Tese (Doutorado em Produção Vegetal) - Universidade Federal de Santa Maria, Santa Maria, 2005.

MURPHY, S. D. Promotion of weed species diversity and reduction of weed seed banks with conservation tillage and crop rotation. Weed Sci., v. 54, n. 1, p. 69-77, 2006.

NORSWORTHY, J. K. et al. Differences in weed tolerance to glyphosate involve different mechanisms. Weed Technol. v. 15 , n. 4 , p. $725-731,2001$

PANDEYA, S. C.; PURI, G. S.; SINGH, J. S. Research methods in plant ecology. New York: Asia Publishing House, 1968. 272 p.

PUTNAM, A. R.; DeFRANK, J. Use of phytotoxic plant residues for selective weed control. Crop Protec., v. 2, n. 1, p. 173-181, 1983.
R DEVELOPMENT CORE TEAM. R: A language and environment for statistical computing. Vienna: $R$ Foundation for Statistical Computing, Austria, 2011. Disponível em: <http://www.R-project.org/>. Acesso em: 22 mar. 2012

SILVA, A. A. et al. Biologia de plantas daninhas. In: SILVA, A A.; SILVA, J. F., ed. Tópicos em manejo de plantas daninhas. Viçosa, MG: Universidade Federal de Viçosa, 2007. p. $17-61$

SNEATH, P. H.; SOKAL, R. R. Numerical taxonomy: the principles and practice of numerical classification. San Francisco: W. H. Freeman, 1973. 573 p.

SOKAL, R. R.; ROHLF, F. J. The comparison of dendrograms by objective methods. Taxon, v. 11, n. 1, p. $33-40,1962$

SOUZA, M. N. Degradação e recuperação ambiental e desenvolvimento sustentável. Viçosa, 2004, $393 \mathrm{f}$. Dissertação (Mestrado em Ciência Florestal) - Universidade Federal de Viçosa, Viçosa, MG, 2004

TESIO, F. et al. Potential allelopathic effects of Jerusalem Artichoke (Helianthus tuberosus) leaf tissues. Weed Technol., v. 24, n. 3, p. 378-385, 2010

VELYKIS, A.; SATKUS, A. Influence of crop rotations and reduced tillage on weed population dynamics under Lithuania's heavy soil conditions. Agron. Res., v. 4, n. 2, p. 441-445, 2006.

VOLL, E. et al. A dinâmina das plantas daninhas e práticas de manejo. Londrina: Embrapa Soja, 2005. 85 p. (Embrapa Soja. Documentos, 260).

VOLL, E. et al. Chemical interactions of Brachiaria plantaginea with Commelina benghalensis and Acanthospermum hispidum in soybean cropping systems. J. Chem. Ecol., v. 30, n. 7, p. 1467-1475, 2004. 